
April 1942

\title{
CREEP RATES OF COLD-DRAWN NICKEL-COPPER ALLOY (MONEL METAL)
}

\author{
By John A. Bennett and Dunlap J. McAdam, Jr.
}

\section{ABSTRACT}

A description is given of new equipment recently assembled at this Bureau for testing the creep of metals.

The apparatus was used to study the creep rate of cold-drawn nickel-copper alloy over a wide range of stress and temperature. Each specimen was used for a series of tests, which allowed a more rapid determination of the characteristic creep rates than using a single specimen for each test. The data indicate that the characteristic creep rate depends only on the stress and temperature, and is not affected by prior stresses or temperatures. The influence of stress on the rate of creep increases with increasing stress, while the influence of temperature on the rate of creep decreases with increasing temperature. The results of the tests are shown in graphs, as no mathematical expression was found which would represent them.

\section{CONTENTS}

Page

I. Introduction _

II. Apparatus _...

1. Specimen and methods of loading 418

2. Furnaces and temperature control_... _ _ _ _ _ 419

3. Measurement of extension ....... 421

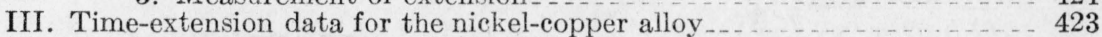

1. Procedures and material _............ 423

2. Results from specimens supporting different loads at the same

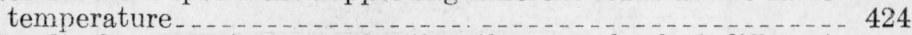

3. Results from specimens supporting the same load at different temperatures ............. 431

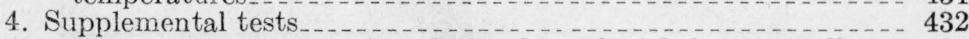

IV. The stress-temperature creep-rate relationship of nickel-copper alloy _- 434

V. Summary and conclusions....

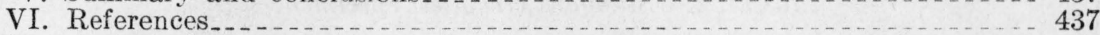

\section{INTRODUCTION}

It is well known that if the temperature is sufficiently high, all metals will deform continuously under a constant stress. This time rate of change of deformation is called creep. About 20 years ago it began to be realized that the tensile strength as determined by a short-time test does not give reliable information on the ability of metals to withstand stress at elevated temperature and that such information can be obtained only by measuring the deformation of the material over long periods of time.

A considerable amount of the pioneer work on the creep of metals 
was done by H. J. French and associates [1] ${ }^{1}$ at this Bureau. Since then there has been great improvement in creep-testing equipment. For the present investigation at this Bureau, therefore, it was necessary to design new apparatus in accordance with present standards. This apparatus is described in the first part of this report.

In the temperature range where creep occurs, the instantaneous elastic extension is followed by plastic extension at a decreasing rate. If this plastic extension is plotted against time, the slope is found to approach a constant value whose magnitude depends on the stress and temperature. The period of decreasing creep rate is followed by a period of increasing rate, which leads to fracture. For comparatively low stresses and temperatures (such as those which would be encountered in service), the period of decreasing creep is so long that it is not practicable to run tests until the fracture period starts. This fact makes it difficult to define a creep rate which is characteristic of a certain stress-temperature combination. However, since the creep rate during much of the decreasing period is very nearly constant, it has been found possible to estimate a characteristic rate from the time-extension diagram after the initial rapid change in rate.

This paper gives results showing the influence of stress and temperature on this characteristic creep rate for a single material. A nickel-copper alloy was chosen in order that the results would not be complicated by allotropic transformations and by the presence of more than one phase.

\section{APPARATUS}

\section{SPECIMEN AND METHODS OF LOADING}

The new apparatus consists of 12 static tensile testing units each fitted with a furnace for maintaining the specimen at a uniform and

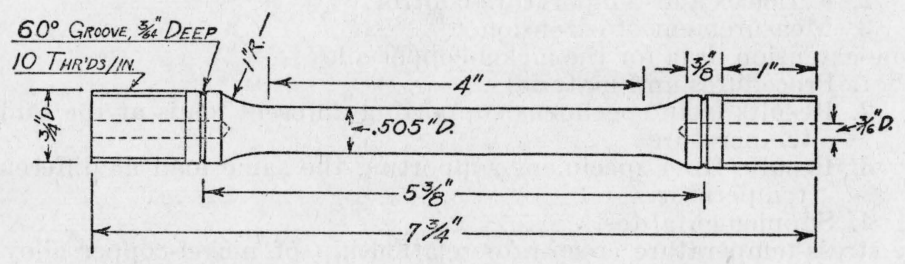

Figure 2.-Standard creep-test specimen.

constant temperature over long periods. Tensile creep tests were decided upon in preference to other types-such as bending, torsion, etc.-because of the uniformity of the stress distribution.

To conserve space, the loading framework was made as compact as possible by putting 12 units in 2 opposed, staggered rows, with the weights of 1 row hanging near the furnaces of the other. The whole framework, one side of which is shown in figure 1, rests on compression springs to reduce vibration. The standard specimen for use in the apparatus has a 4 -in. gage length of 0.505 -in. diameter (fig. 2). Universal joints are used above and below the specimen adapters to reduce nonaxial loading.

\footnotetext{
1 Figures in brackets indicate the literature references at the end of this paper.
} 


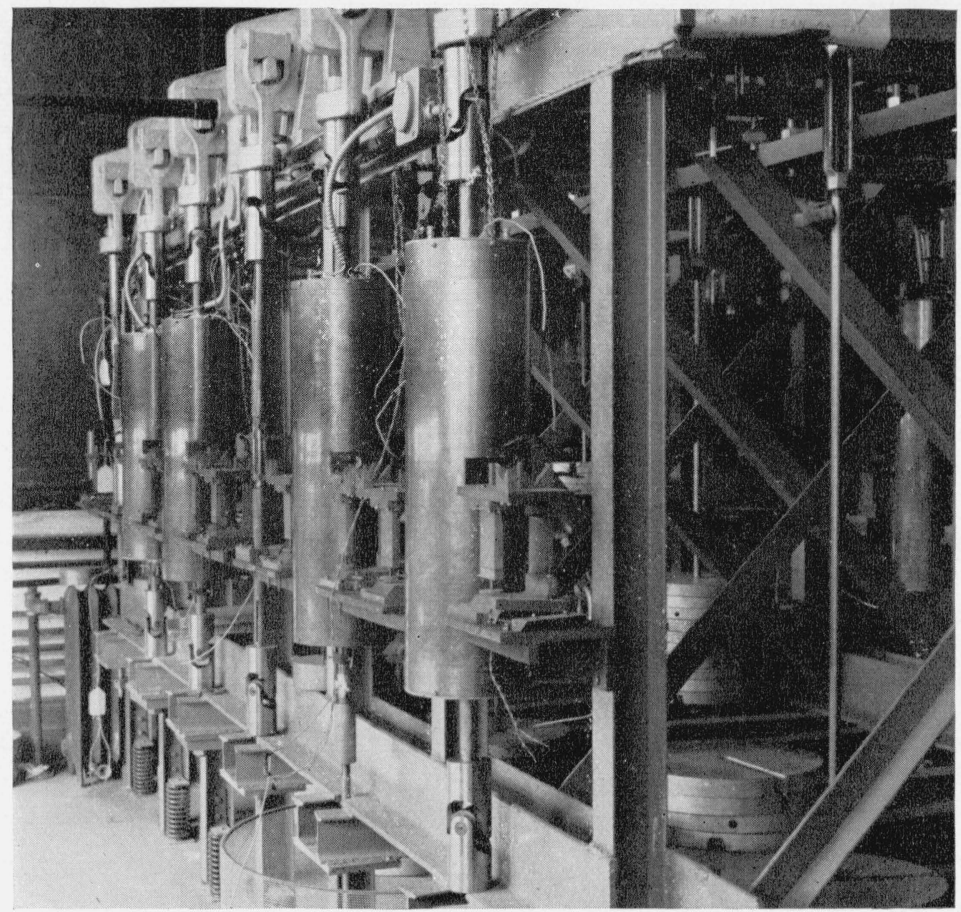

Figure 1.-Creep-test apparatus.

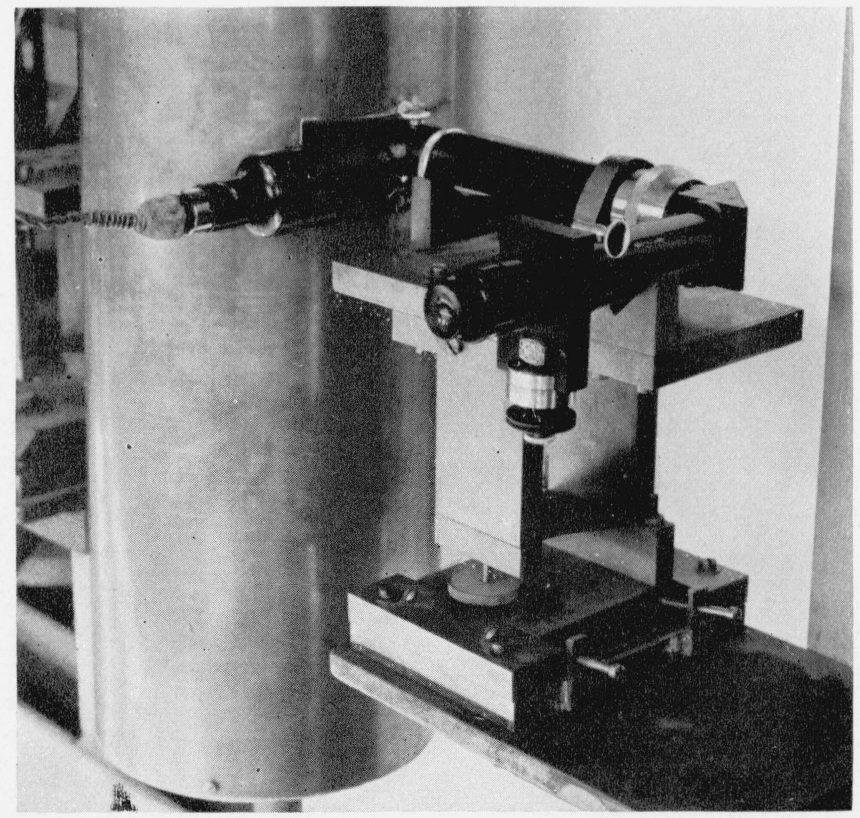

FIGURE 5.-The extensometer microscope in place at a creep furnace. 
In order to maintain suitable accuracy in the application of low stresses without the necessity of using an excessive number of weights for applying large loads, three loading systems have been provided. For low stresses the weights are hung directly on the specimen, at $A$ in figure 3. For intermediate stresses a single lever having a ratio of 9:1 is used with the weights loaded at $B$. In the highest range of stress, two levers having an over-all factor of $54: 1$ are used with weights hung at $C$. In this way stresses as low as $80 \mathrm{lb}$./in. ${ }^{2}$ and as high as $90,000 \mathrm{lb} . / \mathrm{in}^{2}{ }^{2}$ can be applied easily and accurately.

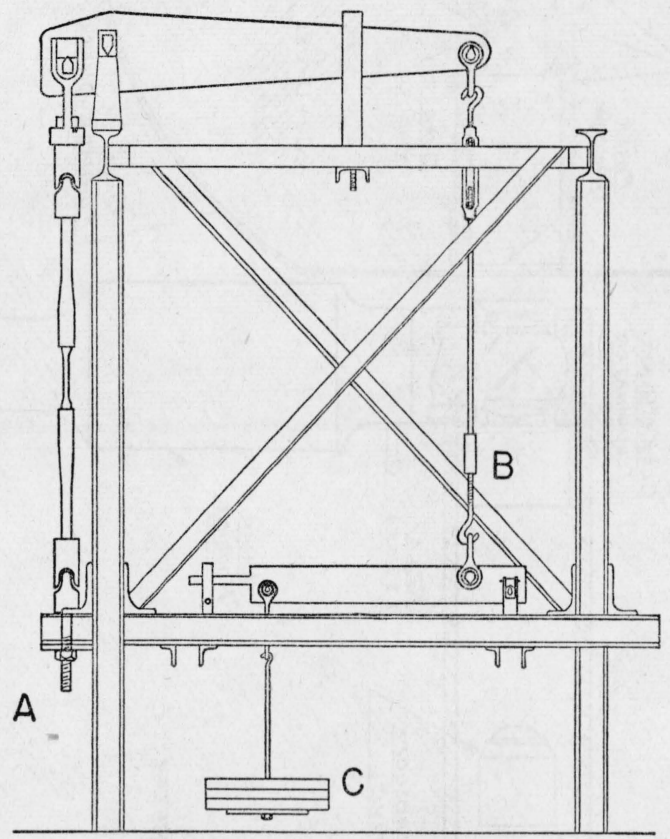

Figure 3.-Methods of loading the specimen.

1. Low stresses; weights are loaded at $A$. 2. Intermediate stresses; weights are loaded at $B$. 3. High stresses; weights are loaded at $C$.

\section{FURNACES AND TEMPERATURE CONTROL}

The furnaces are the conventional tube type, the over-all dimensions being 24 in. long by 7 in. in diameter. The Alundum inner tube has a $1 \frac{1}{2}$-in. bore, and the space between this tube and the outer brass shell is filled with Sil-O-Cel insulation. At the center of each furnace are two windows $180^{\circ}$ apart for sighting on the gage bars. These windows consist of Alundum tubes, closed on the inside by a quartz disk set into the furnace tube, and on the outside by a Pyrex disk (fig. 4). The furnace winding is spaced to give, as nearly as possible, uniform temperature along the gage length, and four taps are provided for final temperature adjustment.

In each furnace there are three thermocouples, for controlling, recording, and checking the furnace temperature. All of the couples may be read with a stationary precision potentiometer by selecting the desired couple on multiple-point switches.

The location of the control couple is important. If it is outside 
the winding, the furnace temperature varies with the room temperature. This variation can be eliminated by placing the bead of the couple inside the winding. This is done by drilling two holes in the

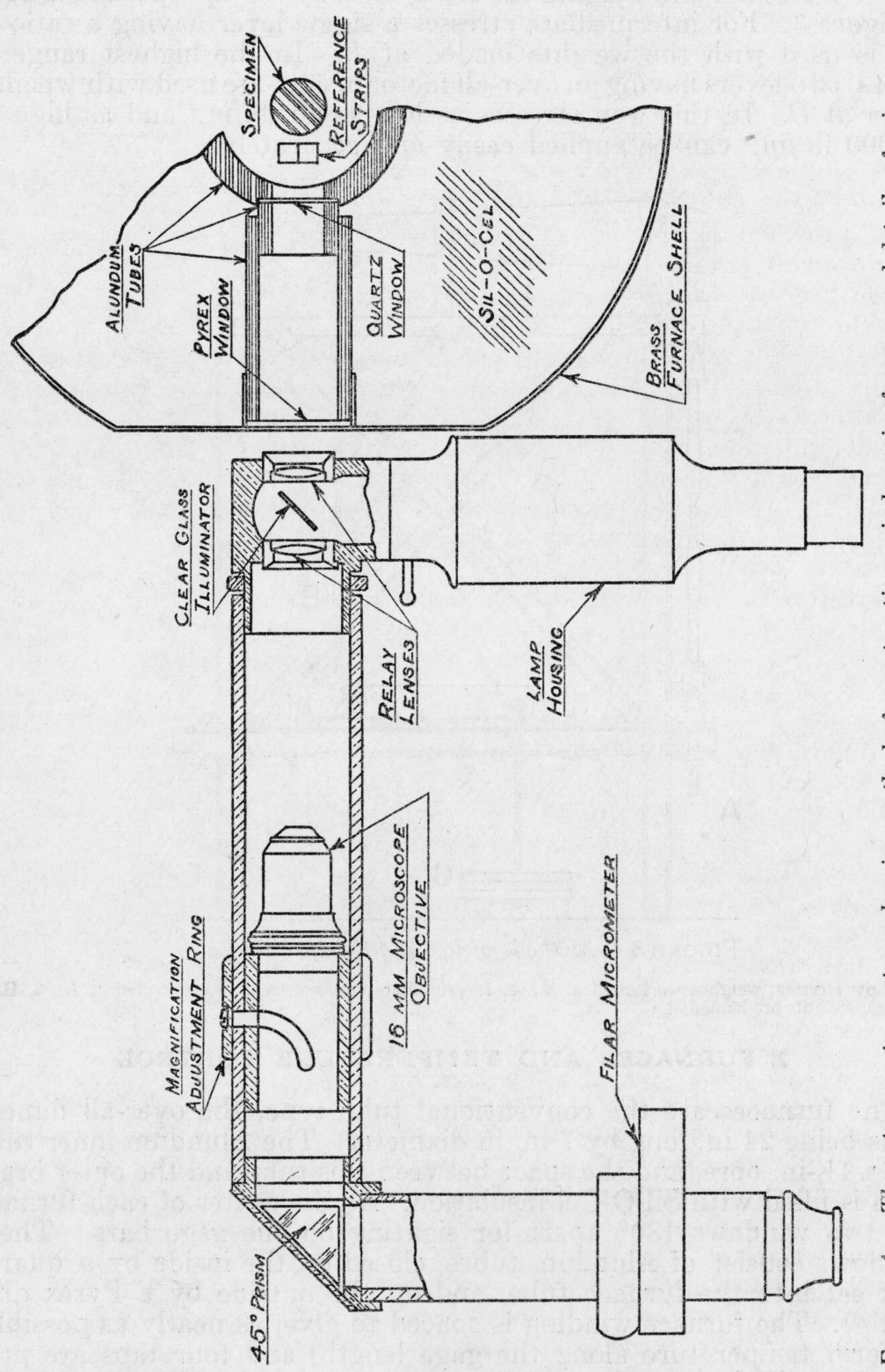

Alundum tube so that they intersect under the heating wire, placing the bead at the intersection, and filling the holes with Alundum cement. The control couple for each furnace is connected to a photoelectric-type controller which changes the power input to the furnace by 25 or 30 percent between off and on. The cold junctions 
of the control thermocouples are kept in constant-temperature boxes mounted on the framework. These boxes are controlled by a bimetal strip at a temperature somewhat higher than the maximum probable room temperature.

The recording and checking couples are placed in holes at each end of the specimens (fig. 2), and the lead wires are brought out through longitudinal holes in the adapters. The recording couple in the top shoulder of the specimen is connected to a six-point recording millivoltmeter, but this gives only a rough measure of the actual temperature and is supplemented every few days by reading the electromotive force of the third couple, which is in the bottom shoulder, with the cold junction in ice. Either of these couples may be removed for comparison against a standard without disturbing the test. With these precautions, the temperature at any one point on a specimen is held constant during a test within less than $\pm 2^{\circ} \mathrm{F}$.

Before a test is started, the furnace is calibrated to give a uniform temperature along the gage length by placing suitable resistances in parallel with certain sections of the winding. The temperature distribution is determined on a dummy specimen of the same dimensions as the test spacimen, but having five thermocouples placed 1 in. apart along the reduced section. Norton [2] stated that this method of calibration was unsatisfactory owing to the variation in heat conductivity across the threads to the adapter with different specimens and different loads. He recommends having thermocouples fastened along the gage length throughout the test. In the present investigation, one actual test specimen was set up in this way in order to see if it was necessary with the 24 -in. furnaces. No significant difference in the temperature distribution along the specimen could be found, either between the dummy and the test specimen or for stresses from 10,000 to $65,000 \mathrm{lb} /$ in $^{2}$.

The variation of temperature along the gage length was not more than $\pm 5^{\circ} \mathrm{F}$, and in most cases was considerably less. There was a section opposite the windows which was slightly cool in all of the furnaces, but the rest of the specimen was in all cases within $\pm 3.5^{\circ} \mathrm{F}$.

Abrupt changes in the room temperature are eliminated by thermostatically controlled heating or ventilating, but no effort is made to maintain the same temperature winter and summer.

\section{MEASUREMENT OF EXTENSION}

The extensometer is of the optical type, with no parts extending out of the furnace (figs. 4 and 5). Extension is determined by measuring the distance between reference marks on two adjacent gage bars with a microscope. One end of each bar is fastened to a shoulder of the specimen, the other ends of the bars being held by a guide in such a way that they are free to slide along one another when the specimen is deformed. The gage bars are Nichrome, but the reference marks are made on platinum strips welded to these bars so that the marks remain well defined after long exposure to elevated temperatures. Each specimen is provided with two pairs of gage bars placed $180^{\circ}$ apart. 
The measuring microscope consists of a relay lens which forms a full-size image of the reference marks, followed by a $16-\mathrm{mm}$ objective and $7.5 \times$ eyepiece which give a magnification of about 75 diameters. The magnification can be adjusted by means of a collar which moves the objective relative to the relay lens and eyepiece. In order to observe the two pairs of gage bars from the front of the frame, a rightangle prism was placed between the objective and eyepiece. Actual measuring is done with the filar micrometer. The extensometer microscope can be easily moved from one unit to another. All the focusing is done by moving the whole mounting, so once this is done properly, the extensometer is always in focus when set in the V-blocks which support it.

The relay lens has a diameter of $0.6 \mathrm{in}$. and a working distance of 3 in., giving a numerical aperture of 0.10 and a theoretical resolving

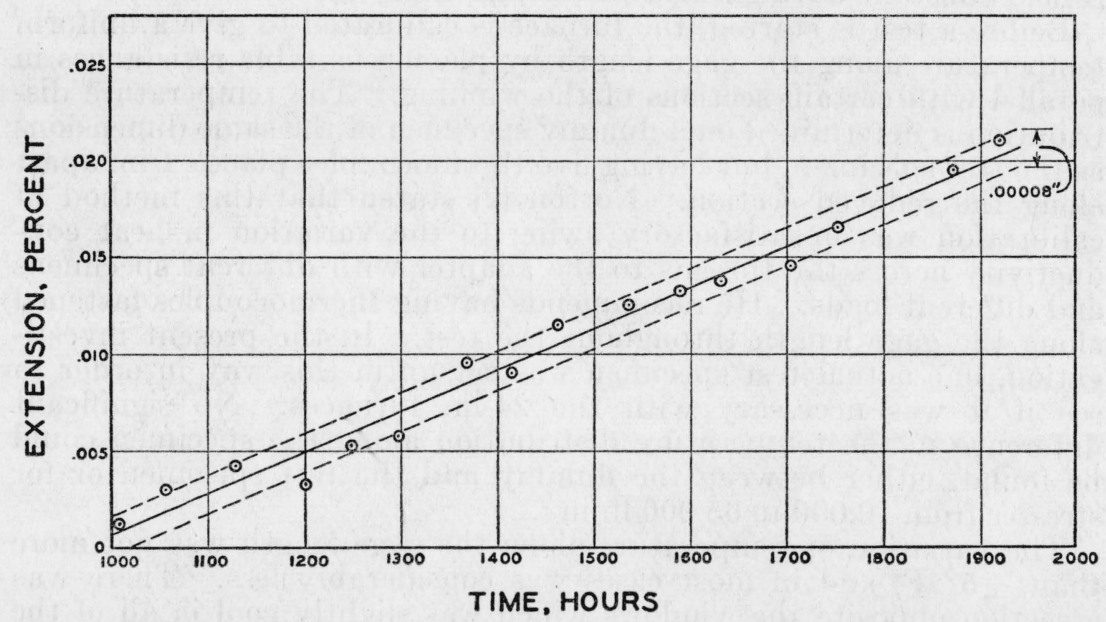

Figure 6.-Portion of a typical creep curve, showing the precision of the observed extension values.

power of about 4 microns for yellow light. This resolving power is sufficient so that by averaging two readings for each observation of the extension, the probable error of an observation is less than 1 micron (0.00004 in.), or 0.001 percent of the gage length. There are several other factors which may cause an error in the measurement of extension, such as variation in temperature of the specimen, change in the positioning of the microscope relative to the gage bars, inequalities in the pitch of the micrometer screw, etc. Figure 6 shows the deviations from a straight line of a series of observations on a typical creep test, and indicates that the combined influence of all the abovementioned factors results in a precision of \pm 1 micron. The dashed lines in this figure are drawn a distance of 1 micron above and below the best average line through the points.

Several checks on the accuracy of the extensometer are provided. The magnification of the microscope is set at a value which gives a convenient conversion factor, and this setting is checked at intervals 
by measurements on a stage micrometer. The total extension of the specimen as measured with the extensometer is checked by measuring, before and after testing, the distance between the grooves on the shoulders of the specimen. The extension as measured by the extensometer must be corrected for the deformation in the shoulder of the specimen. This correction is made from the uncorrected stressrate relationship, assuming a uniform stress distribution throughout the cross section in the fillet (neglecting the part of the shoulder whose diameter is larger than the root of the groove). Measurements on the reduced section indicated that these assumptions and approximations give a sufficiently good approach to the true correction. Before a test is started, small platinum beads are welded at each end of the gage length, and the distance between reference marks made on these beads is measured before and after test. The average difference between the total plastic extension measured in this way and that obtained from the corrected extensometer readings is 1.5 percent for the specimens included in this report.

When the creep rate is high (above about 0.5 percent per 1,000 hours) and maximum precision is less important than the ease and rapidity with which readings can be made, the extensometer field is photographed with a $35-\mathrm{mm}$ camera, and the extension measurements are made later by projecting the negatives in an enlarger. For very high rates of creep ( 5 percent per 1,000 hours or more), the movement of the end of the loading lever is measured with a dial gage, and the extension of the specimen is determined from these measurements by calibrating them with camera or micrometer observations.

\section{TIME-EXTENSION DATA FOR THE NICKEL-COPPER ALLOY}

\section{PROCEDURES AND MATERIAL}

When a metal is subjected to stress and elevated temperature, the various factors influencing its resistance to deformation gradually approach a condition of equilibrium as evidenced by the approach of the creep rate to a constant value. Since the metal actually undergoes alteration during this period, it is difficult to correlate the equilibrium rates for different stress-temperature combinations. In order to minimize the time required for this alteration of the metal, however, a single specimen was used for several different stress-temperature combinations. After each change of stress, the rate was determined shortly after the period of rapid change.

To obtain information concerning the effect of the alteration in structure of the metal, several different procedures were used in determining characteristic rates. In some cases the temperature was held constant and the rate determined for a series of progressively higher stresses (up-step procedure) or for progressively lower stresses (down-step procedure). Most of the results given in this report were obtained with one or the other of these procedures or a combination of the two. It was thus possib?e in many instances to obtain characteristic rates for certain stresses at different stages in the total plastic extension of a specimen. Another procedure was to 
maintain the load constant and determine the characteristic rate at various temperatures.

The material from which specimens were made was 7/8-in. rod of nickel-copper alloy provided by the International Nickel Co. Since it was desired to run tests on both the annealed and cold-worked material, the stock was cold-drawn to a reduction of area of 40 percent, which was sufficient to give uniform hardness and microstructure throughout the cross section. All of the specimens came from the same heat. The composition of the monel metal used in the tests was as follows:

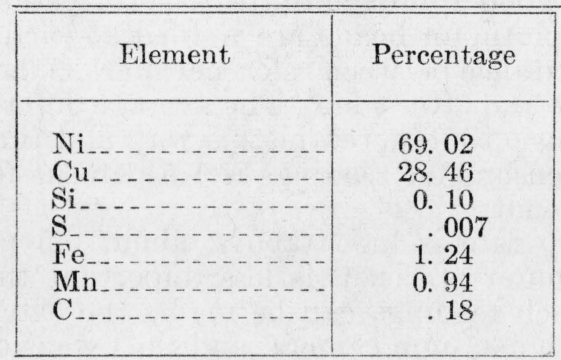

\section{RESULTS FROM SPECIMENS SUPPORTING DIFFERENT LOADS AT THE SAME TEMPERATURE}

Tests in which the temperature was held constant throughout a series were made at the following temperatures; 700,800 (two series), $905,1,000,1,100,1,225^{\circ} \mathrm{F}$. The creep curves for six of these series are shown in figures 7 to 12 , inclusive. As the test at $700^{\circ} \mathrm{F}$ is still in operation, this series is not shown in the figures. The points plotted are the experimental points, and have not been corrected for the extension of the fillet. Each figure shows the results obtained on a single specimen at a single temperature. The time scale was started from zero each time the load was changed, but the ordinates give the total extension of the specimen. The chronological order of the tests is given by the letter adjacent to each curve, while the stress is shown by the numbers above or below each curve. The asterisks near certain curves indicate that these curves were not used in determining the characteristic creep rate. Reasons for this distinction are discussed later. 


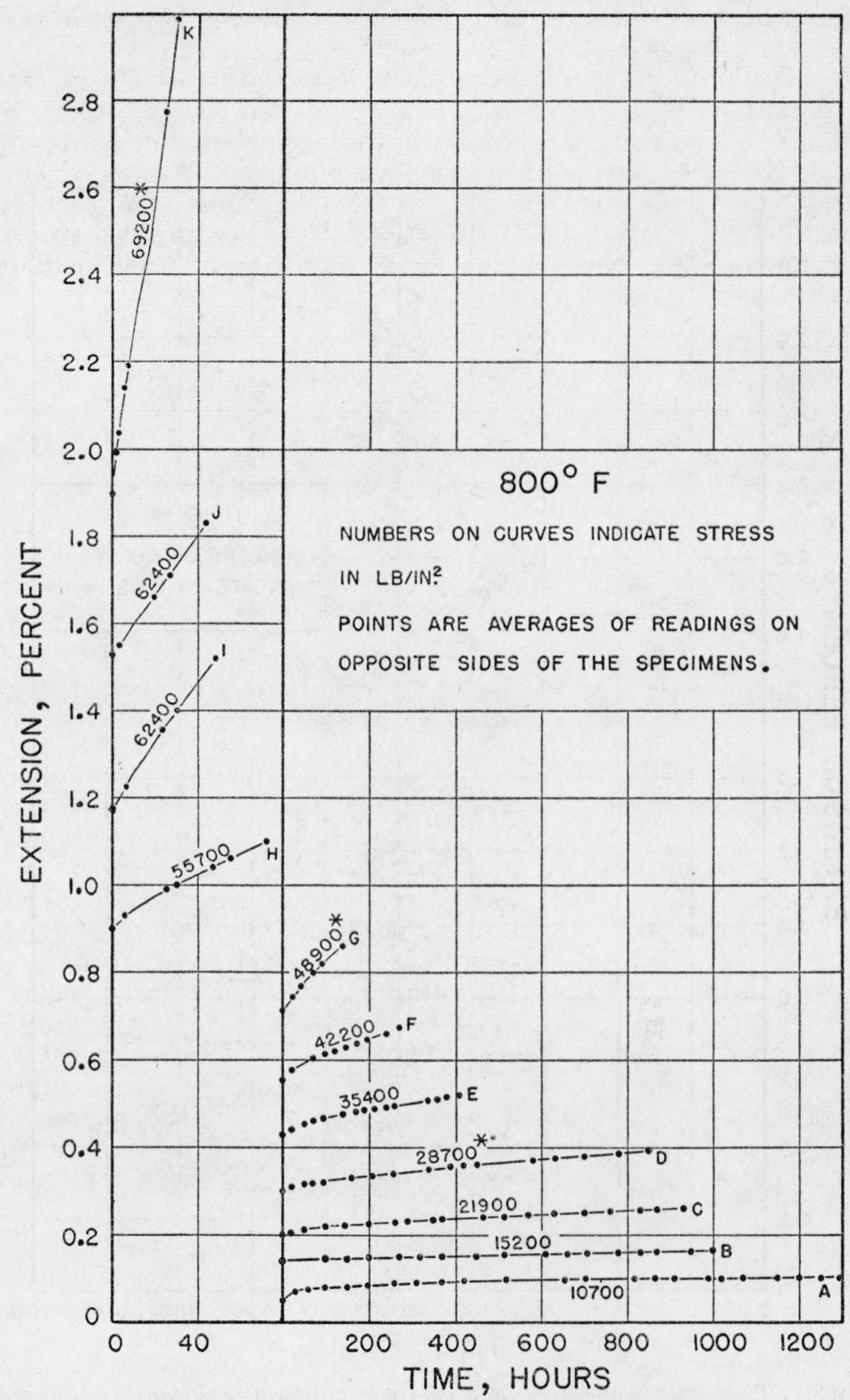

FigURE 7.-Time-extension curves for a specimen supporting various loads at $800^{\circ} \mathrm{F}$. The chronological order of the tests is indicated by the letters on the curves. 


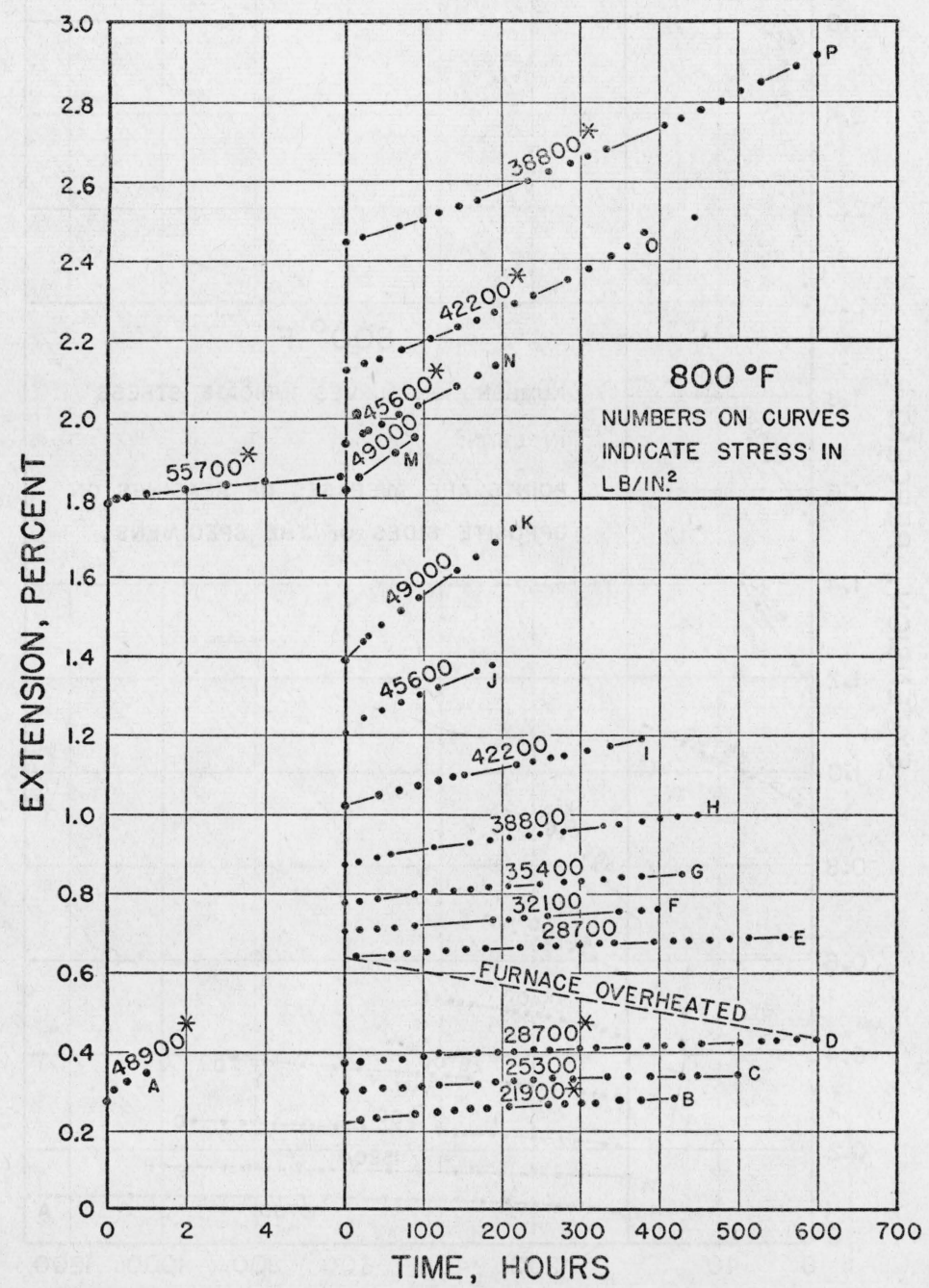

FIGURe 8.-Time-extension curves for a specimen supporting various loads at $800^{\circ} \mathrm{F}$. The chronological order of the tests is indicated by the letters on the curves. These tests were made on a different specimen from those shown in figure 7. 


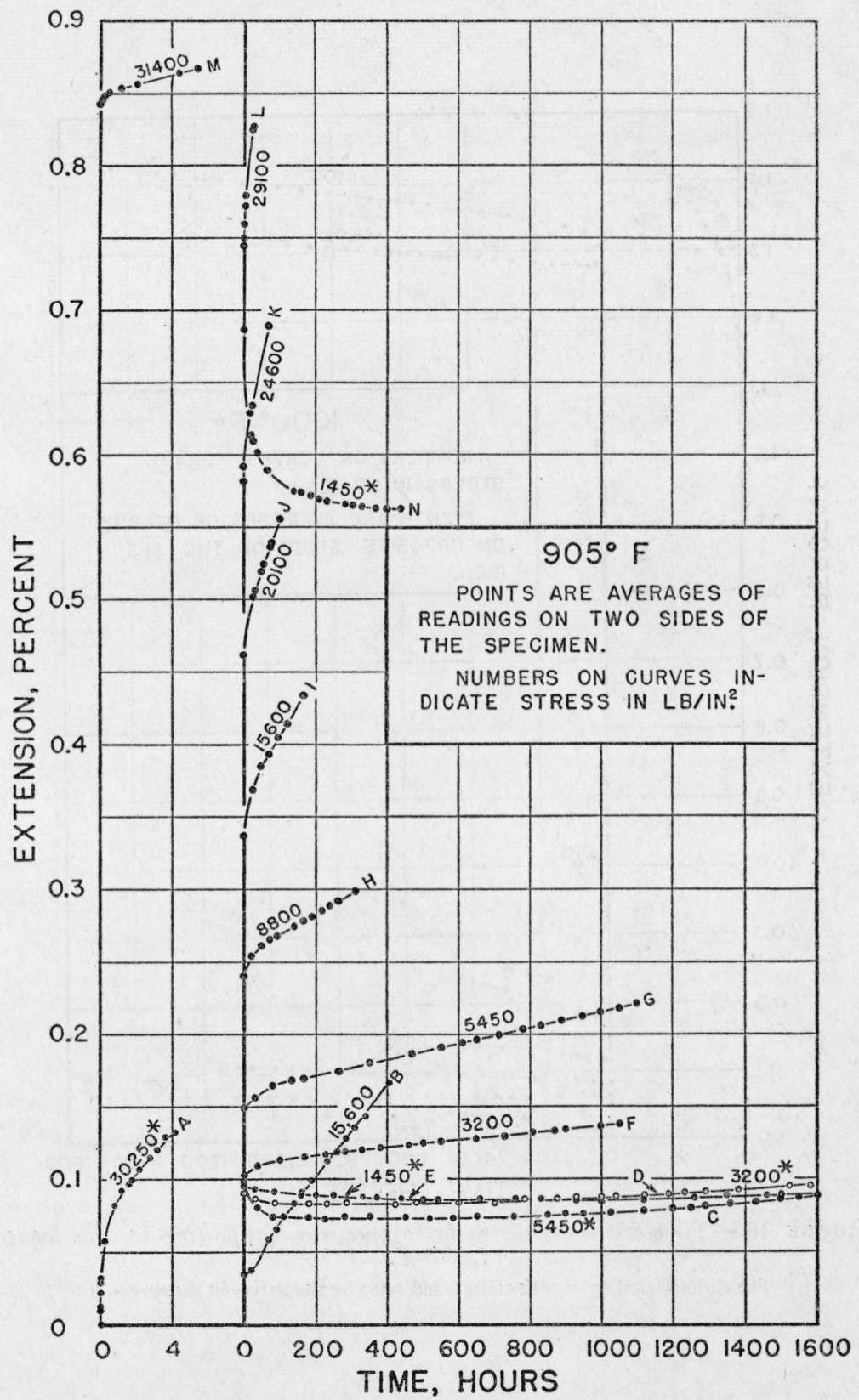

Figure 9.-Time-extension curves for a specimen supporting various loads at $905^{\circ} \mathrm{F}$.

The chronological order of the tests is indicated by the letters on the curves. The elastic extension occurring upon application of the first load is not shown. 


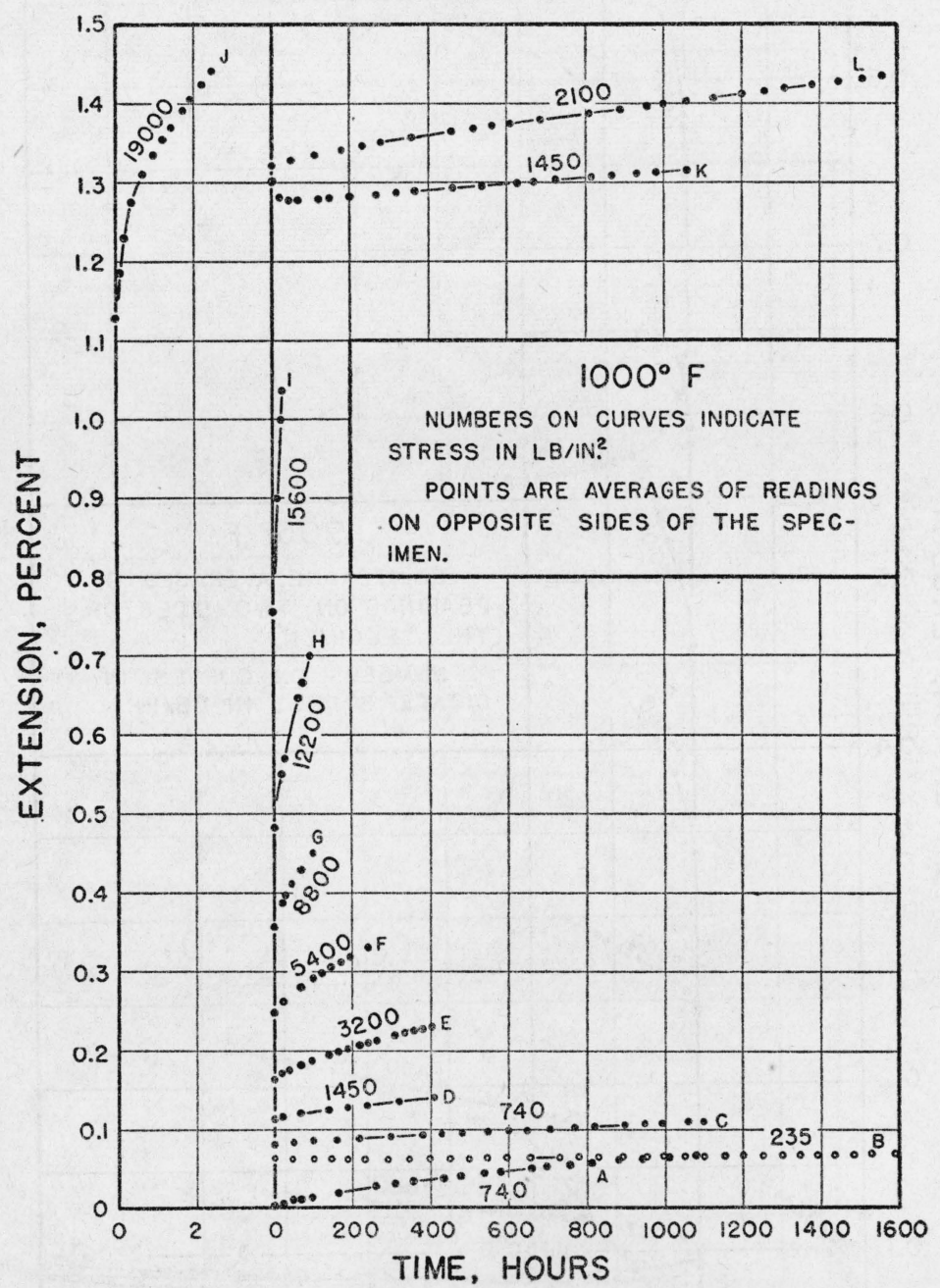

Figure 10.-Time-extension curves for a specimen supporting various loads at $1,000^{\circ} \mathrm{F}$.

The chronological order of the tests is indicated by the letters on the curves. 


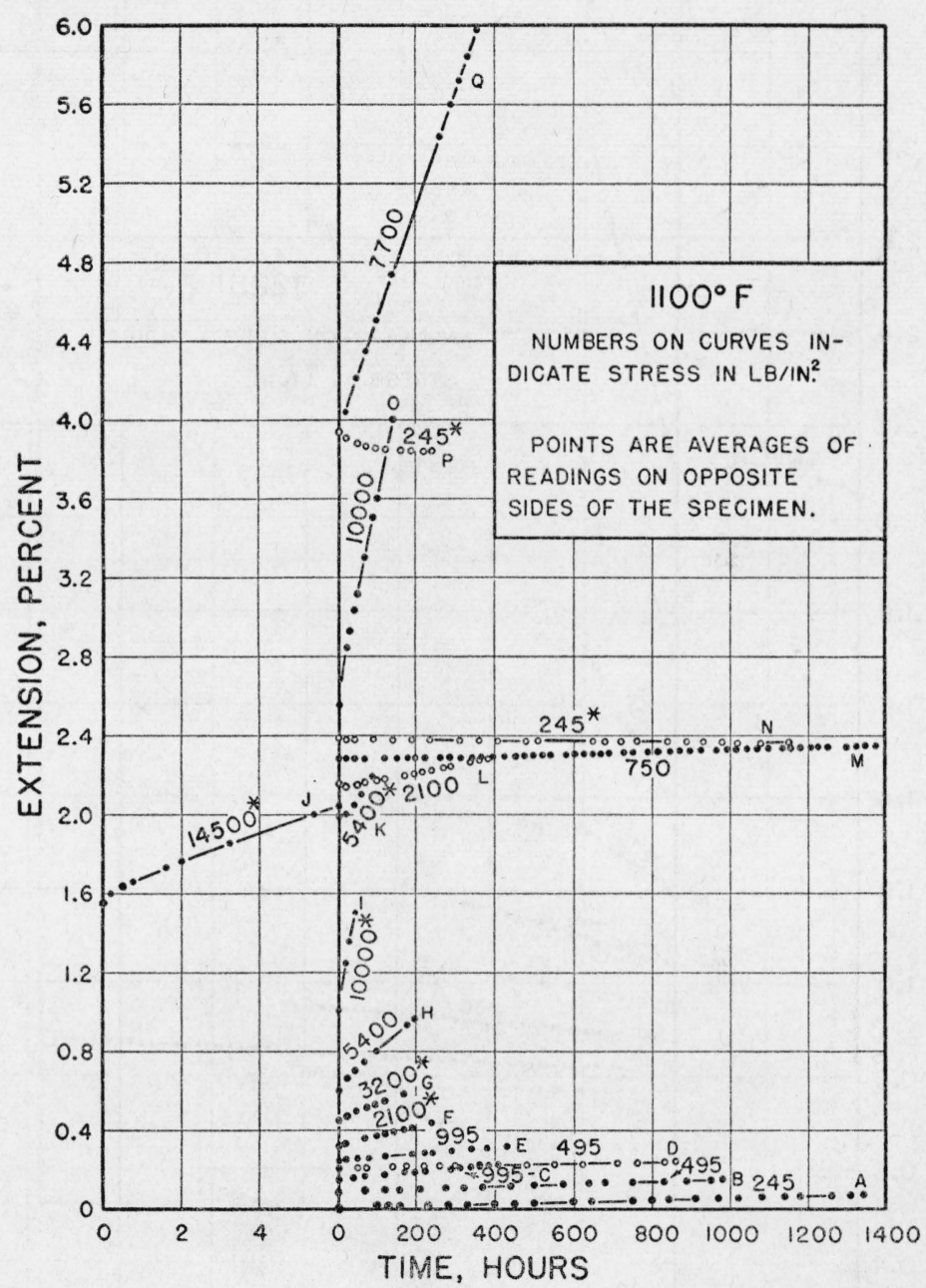
FIgure 11.-Time-exiension curves for a specimen supporting various loads at

The chronological order of the tests is indicated by the letters on the curves. 


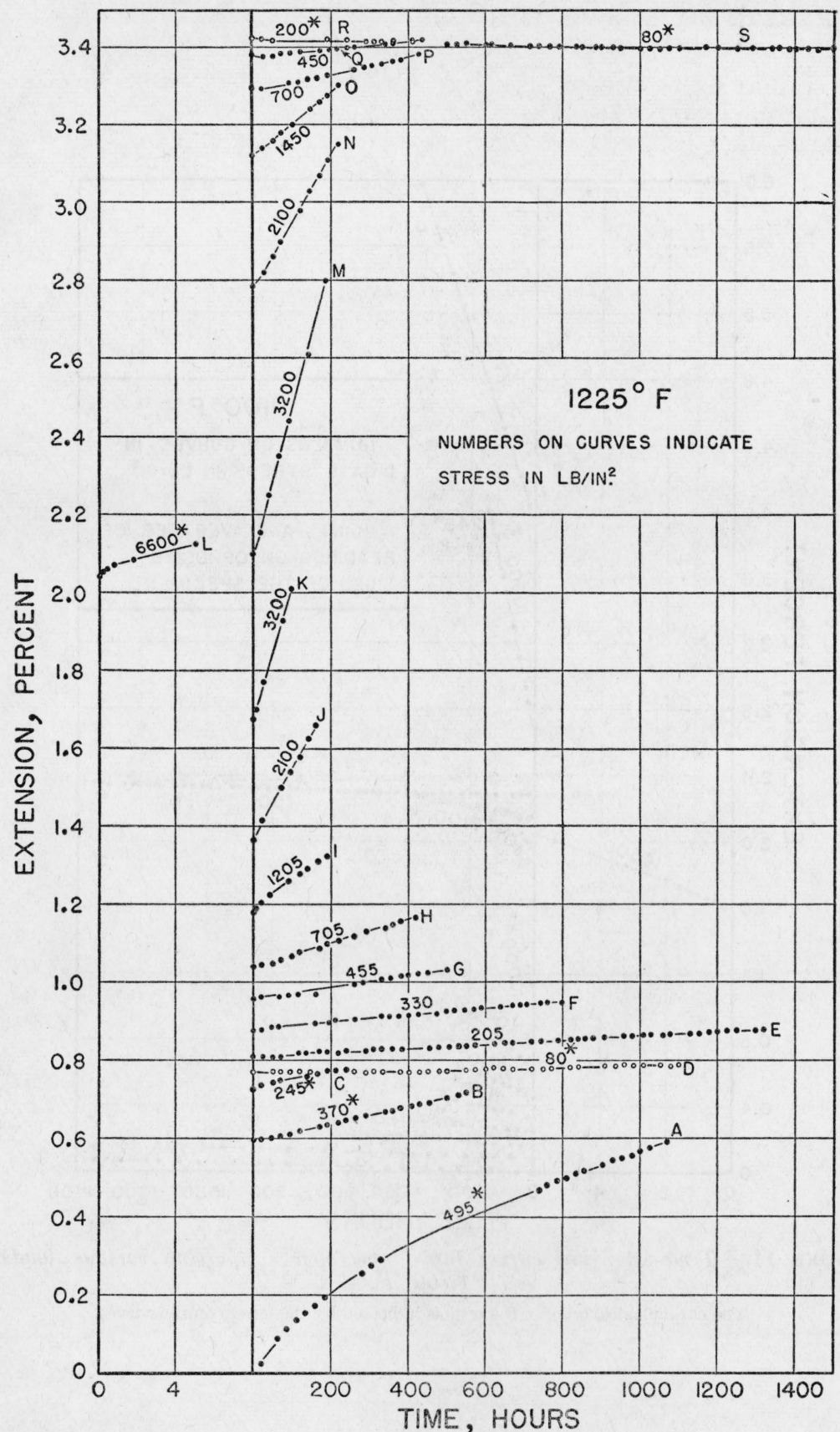

FIGURE 12.-Time-extension curves for a specimen supporting various loads at $1,225^{\circ} \mathrm{F}$.

The chronological order of the tests is indicated by the letters on the curves. 


\section{RESULTS FROM SPECIMENS SUPPORTING THE SAME LOAD AT DIFFERENT TEMPERATURES}

A similar series of curves is shown in figure 13 for the tests made by holding the load constant and varying the temperature between tests. Because the relative thermal expansion of the specimen and the exten-

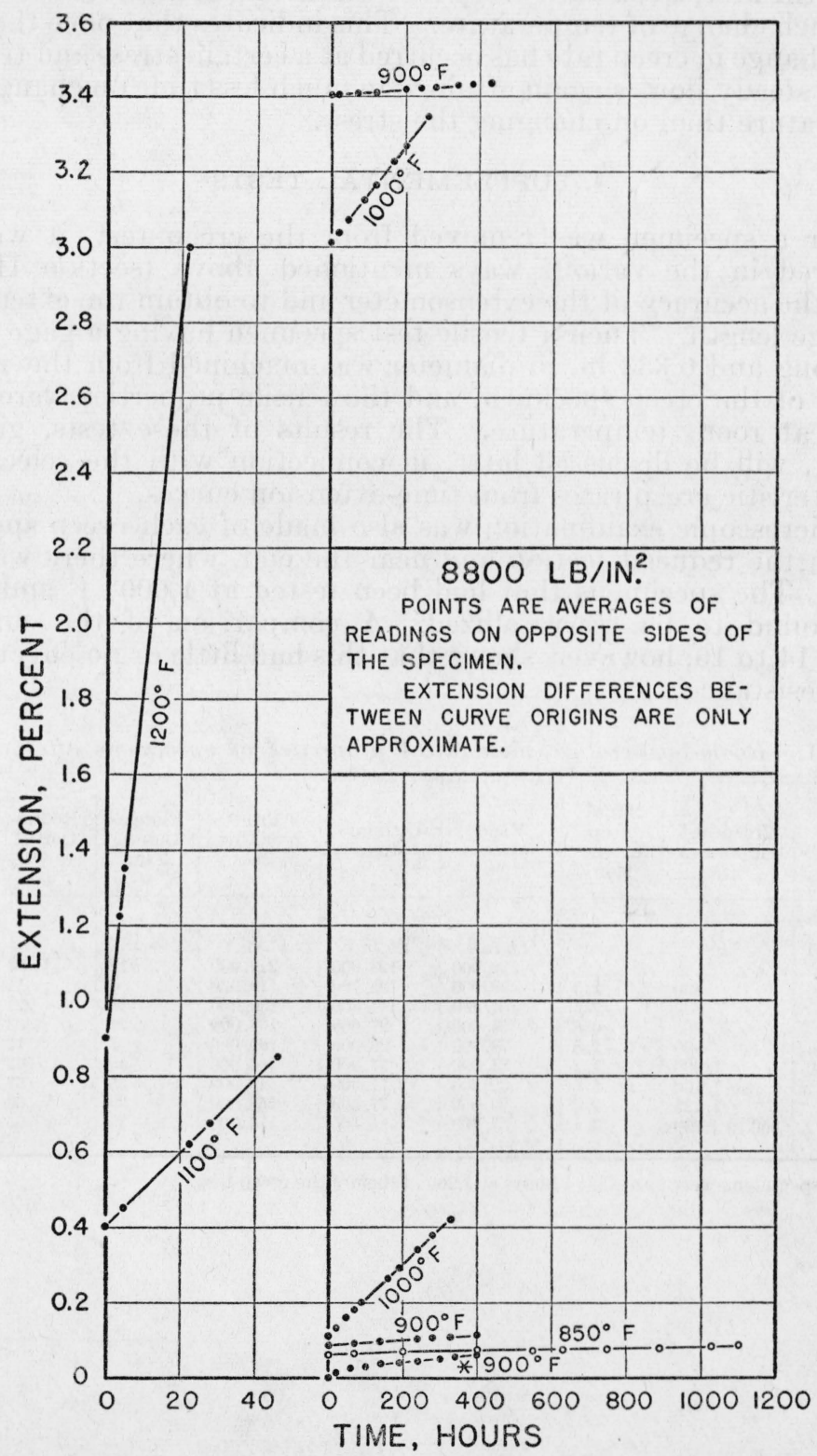

FIGURE 13.-Time-extension curves for a specimen supporting a load of $8,800 \mathrm{lb} / \mathrm{in}^{2}{ }^{2}$ at various temperatures.

The chronological order of the tests is indicated by the position of the curves above the $x$ axis.

$446682-42-3$ 
someter bars was not known with much accuracy, the extension which took place during the periods when the temperature was being changed could not be determined. Therefore the position of the curves above the base line in the graph must be considered as only approximate.

An inspection of the curves in figure 13 shows that for all tests except the first, a constant creep rate was attained almost immediately after each change of temperature. This indicates that once the initial rapid change in creep rate has occurred at a certain stress and temperature, a steady flow is again attained in much less time on changing the temperature than on changing the stress.

\section{SUPPLEMENTAL TESTS}

After a specimen was removed from the creep test, it was first measured in the various ways mentioned above (section II-3) to check the accuracy of the extensometer and to obtain the extension of the gage length. Then a tensile test specimen having a gage section 2 in. long and $0.333 \mathrm{in}$. in diameter was machined from the reduced section of the creep specimen, and the tensile properties were determined at room temperature. The results of these tests, given in table 1, will be discussed later, in connection with the selection of characteristic creep rates from time-extension curves.

A microscopic examination was also made of each creep specimen, both in the reduced section and near the end, where there was little stress. The specimens that had been tested at $1,000^{\circ} \mathrm{F}$ and higher were found to be recrystallized. A comparison of the curves in figures 14 to 16 , however, shows that this had little or no effect on the creep resistance.

TABLE 1.-Room-temperature mechanical properties of specimens after creep test

\begin{tabular}{|c|c|c|c|c|c|c|c|c|}
\hline Specimen & $\begin{array}{l}\text { Creep test } \\
\text { temperature }\end{array}$ & $\begin{array}{l}\text { Total } \\
\text { creep } \\
\text { exten- } \\
\text { sion }\end{array}$ & $\begin{array}{l}\text { Yield } \\
\text { stress }\end{array}$ & $\begin{array}{l}\text { Ultimate } \\
\text { stress }\end{array}$ & $\begin{array}{c}\text { True } \\
\text { breaking } \\
\text { stress }\end{array}$ & $\begin{array}{l}\text { Elonga- } \\
\text { tion in } \\
2 \text { in. }\end{array}$ & $\begin{array}{l}\text { Reduc- } \\
\text { tion of } \\
\text { area }\end{array}$ & $\begin{array}{l}\text { Hardness } \\
\text { number }\end{array}$ \\
\hline $\begin{array}{l}\text { O riginal } \\
\text { material } \\
Z A Q \\
7 A 7 \\
Z A B \\
7 A 10 \\
7 A 5 \\
7 A 8 \\
Z B 11 \\
Z B E 1\end{array}$ & $\begin{array}{r}{ }^{\circ} F \\
800 \\
800 \\
905 \\
900 \\
1,000 \\
1,100 \\
1,225 \\
850 \text { to } 1,200\end{array}$ & $\begin{array}{r}\text { Percent } \\
2.3 \\
2.6 \\
0.8 \\
2.8 \\
1.2 \\
5.6 \\
2.5 \\
3.1\end{array}$ & $\begin{array}{r}L b / \text { in } .^{2} \\
122,000 \\
90,000 \\
101,400 \\
64,000 \\
78,800 \\
31,000 \\
32,300 \\
29,000 \\
37,800\end{array}$ & $\begin{array}{r}L b / i n .^{2} \\
128,000 \\
105,700 \\
114,800 \\
97,600 \\
96,000 \\
77,900 \\
77,300 \\
77,500 \\
85,500\end{array}$ & $\begin{array}{c}I b / \text { in . }{ }^{2} \\
219,000 \\
119,000 \\
138,000 \\
163,000 \\
109,000 \\
156,000 \\
146,000 \\
158,000 \\
176,000\end{array}$ & $\begin{array}{r}\text { Percent } \\
12 \\
7 \\
11 \\
21 \\
7 \\
40 \\
35 \\
39 \\
39\end{array}$ & $\begin{array}{r}\text { Percent } \\
64 \\
11 \\
21 \\
53 \\
12 \\
62 \\
57 \\
63 \\
65\end{array}$ & $\begin{array}{r}\text { Ro:kuell } \\
\text { "B" } \\
102 \\
95 \\
99 \\
92 \\
98 \\
65 \\
66 \\
65 \\
83\end{array}$ \\
\hline
\end{tabular}

1 These specimens were annealed 4 hours at $1,200^{\circ} \mathrm{F}$ before the creep test. 


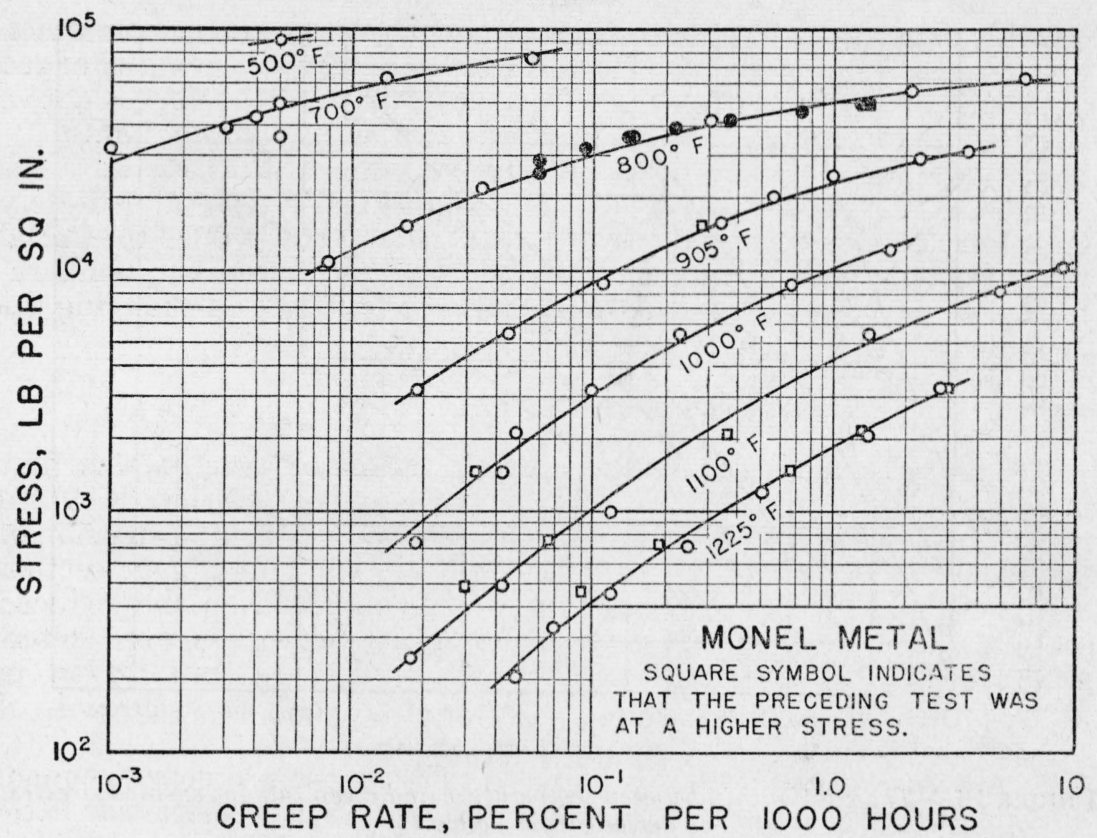

FIGURE 14.-Relationship between stress and creep rate for various temperatures, obtained from the time-extension curves of figures 7 to 12.

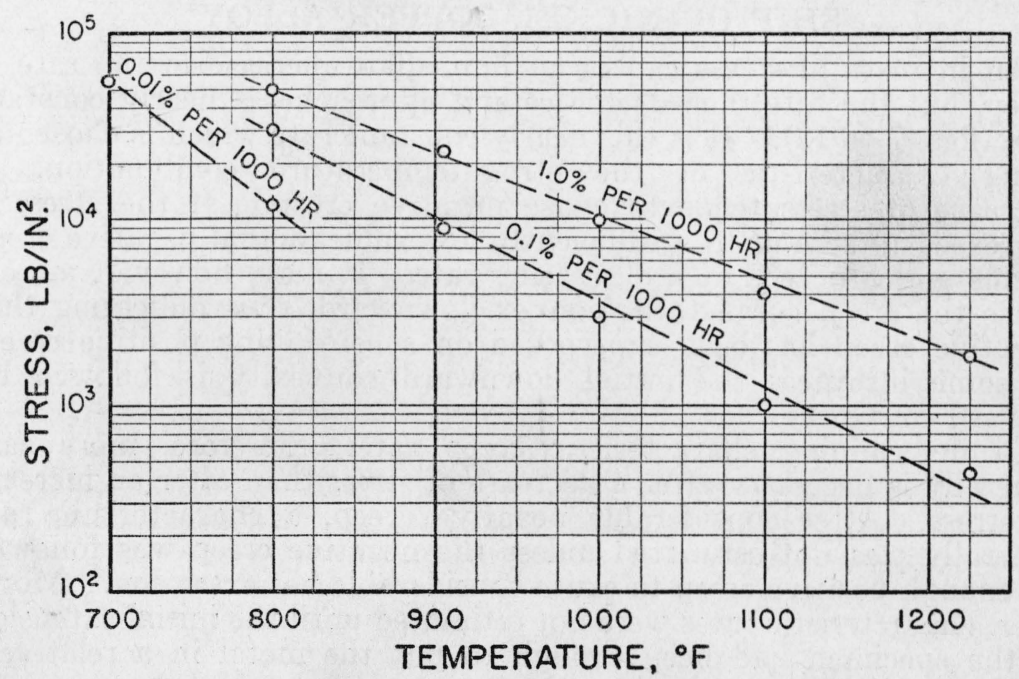

FIGURE 15.-Relationship between temperature and the stress required to produce certain creep rates, as derived from figure 14. 


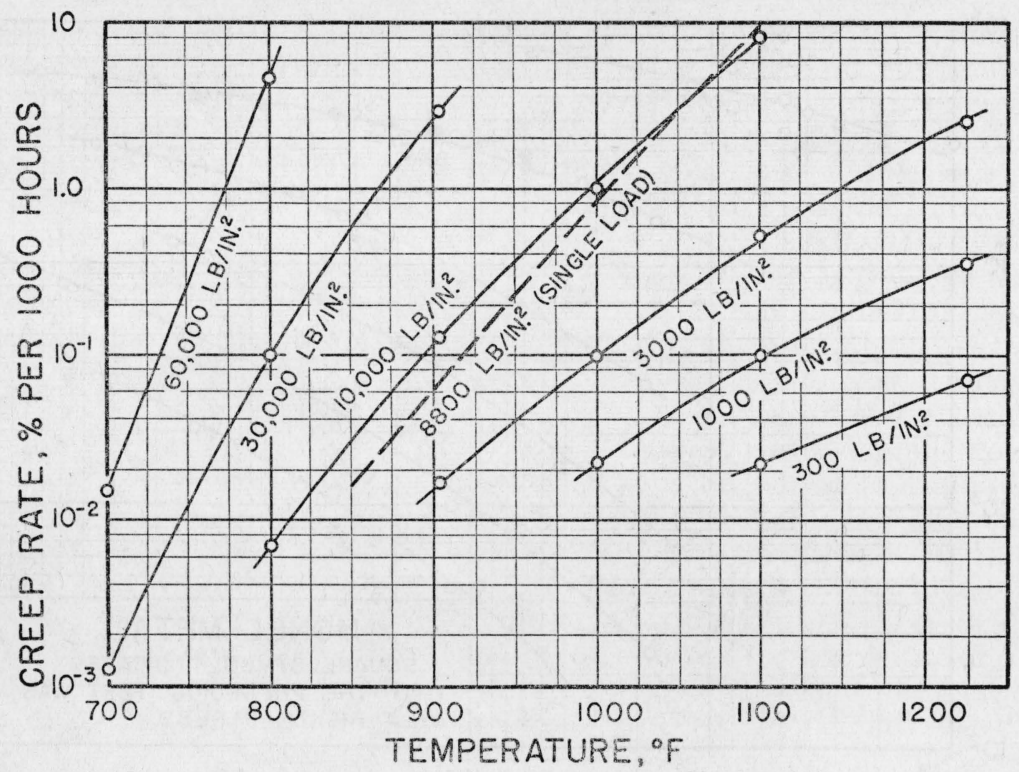

FIGURE 16.-The relationship between temperature and creep rate for various stresses, as derived from figure 14 .

The dashed line is the curve of figure 17.

\section{THE STRESS-TEMPERATURE CREEP-RATE RELATION- SHIP OF NICKEL-COPPER ALLOY}

An increase of stress causes an immediate increase in the rate of creep, but the rate then decreases and approaches a nearly constant rate (figs. 7 to 12). It is this nearly constant rate which is chosen as being characteristic of the stress-temperature combination. A decrease of stress tends to cause negative creep. ${ }^{2}$ If the stress is decreased to zero or to a sufficiently low value, actual negative creep begins and proceeds at a decreasing rate. It may, however, merely cause the creep curve to be convex downward, thus indicating that negative creep has been superposed on a continuing positive creep. In some instances the initial downward convexity is followed by upward convexity.

In determining characteristic creep rates, therefore, more care generally is necessary after a decrease of stress than after an increase of stress. After considerable negative creep, a characteristic rate generally was not estimated unless the negative creep was followed by enough positive creep to cause considerable net extension. Moreover, characteristic rates were not estimated until the initial extension of the specimen had been enough to put the metal in a relatively stable condition as regards resistance to creep. No characteristic creep rates, for example, were estimated from curves $C, D$, and $E$ of figure 9 , or from curves $A$ to $D$ of figure 12. After total extension beyond a certain amount, moreover, creep may tend to proceed at a continuously increasing rate, probably because permanent damage to the material has resulted. Evidence of such permanent damage was seen in the microstructure and in the mechanical properties at room temperature (table 1), the reduction in ductility of the damaged

${ }^{2}$ Negative creep is here used to mean any plastic contraction, regardless of the direction of the stress change preceding it. 
specimens ( $Z A 2, Z A 7, Z A 10)$ being very marked. Such a condition evidently is the cause of the continued downward convexity and the relatively rapid creep rate represented by the upper three curves of figure 8. For these reasons, a few curves at the top of some of the series were not used in estimating characteristic rates. The curves that were not used in estimating characteristic creep rates are indicated by asterisks.

In the actual determination of creep rates, the time-extension data were plotted on larger and more appropriate scales than those of figures 7 to 13, and the correction for extension in the shoulders of the specimen was made. The estimatea characteristic rates are plotted against stress in figure 14 . No consistent differences are found between the experimental points obtainel after a decrease of stress and the points obtained after an increase of stress. These results, therefore, do not confirm the conclusions reached by some investigators as a result of experiments with steels. White and Clark [3] presented results of up-step, down-step, and single-step tests on steel, which indicated that the down-step method of loading gave the lowest creep rate for a certain stress, the single-step method haxt, and the up-step method the highest creep rate. The evidence in figure 14, however, suggests that the direction of previous change of stress has (of itself) practically no effect on the characteristic creep rate.

A comparison between the characteristic creep rate as determined in these tests and the minimum rate, which is reached just before the final stage of creep begins, was provided by a test run at a single load until the rate was definitely accelerating. The temperature was $900^{\circ}$ $\mathrm{F}$, the stress was $30,200 \mathrm{lb} / \mathrm{in} .^{2}$, and the minimum rate, which was reached after 900 hours, was 0.92 percent per 1,000 hours. From figure 14 the characteristic rate at this stress at $905^{\circ} \mathrm{F}$ is 2.8 percent per 1,000 hours.

As indicated by the varying slopes of the curves in figure 14, the influence of a stress variation on the rate of creep increases with increase of the stress, and with decrease of the temperature for a constant rate. Two other aspects of the three-dimensional relationship represented in figure 14 are shown in the derived diagrams, figures 15 and 16. In each of these diagrams, temperatures are represented by linear coordinates. As illustrated by figure 16, the influence of temperature on the creep rate increases with decrease in the temperature (contrary to the prevalent view), and with increase in the stress.

It has been pointed out that the time-extension curves, figure 13, representing data obtained with a specimen supporting the same load at different temperatures, indicate a characteristic rate after a very short adjustment period. These rates are plotted against temperature in figure 17. It will be noted that the relationship can be represented by a curve which is more nearly straight than that representing the stress-rate relationships. This means that the results can be interpolated and extrapolated more reliably than can the stress-rate curves. Kanter and Sticha [4] have suggested the plotting of the logarithm of the creep rate against the reciprocal of the absolute temperature. With the data obtained in this test, however, the resulting curve was not so straight as that in figure 17 .

The curve on figure 17 is included as a dashed line in figure 16 for comparison with the data from the constant-temperature tests. As the agreement evidently is good, it can be concluded that the characteristic creep rate obtained from time-extension data is independent 
of previous temperatures and stresses, and is dependent only on the particular stress-temperature combination.

This conclusion assumes considerable importance when it is remembered that the time-extension curves for tests at constant load and different temperatures show little or no adjustment period. If the conclusion is supported by additional creep-test data, much time evidently may be saved by determining creep rates with this type of test rather than with the conventional single-load constant-temperature tests now commonly used.

Another interesting point is brought out by the agreement between the two types of curves of figure 16. The dashed curve was obtained

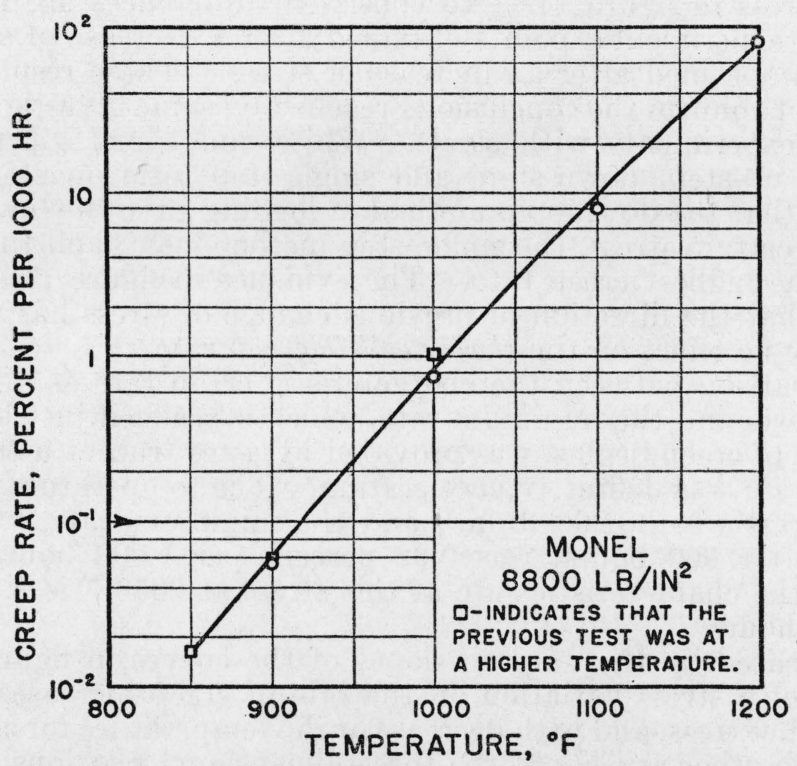

FIgURE 17.-The relationship between temperature and creep rate for a load of $8,800 \mathrm{lb} / \mathrm{in}^{2}{ }^{2}$, as derived from the time-extension curves of figure 13.

on an annealed specimen, while all of the constant-temperature tests (except the one at $1,225^{\circ} \mathrm{F}$ ) were made on cold-drawn specimens. This difference in the material, therefore, evidently has little effect on the characteristic creep rate for this alloy. This does not mean, however, that the rate would be the same if some structural change, such as recrystallization, were taking place during the test.

None of the mathematical relationships suggested in the literature [5] were found to agree with the creep data determined in this investigation, and it is thought that the data can be represented satisfactorily only in graphs. Since the stress-temperature and creep-ratetemperature curves are nearly straight, the relationship between these two pairs of variables may be represented approximately by exponential equations, but the agreement with experiment is not sufficiently close to be of particular value.

The closest approximation to the time-elongation curves is obtained with an equation of the form

$$
d=d_{0}+v t-C e^{-\alpha t},
$$

where $d_{0}, C$, and $\alpha$ are constants, $d$ is total extension, $t$ is time, and $v$ 
is the minimum creep rate. This cannot be made to fit well near the beginning of the test, and is certainly not the true relationship, but it is the only type of equation which gives a reasonably good approach to the curves for both the up-step and down-step tests.

\section{SUMMARY AND CONCLUSIONS}

Details of the creep-testing apparatus recently installed at the National Bureau of Standards are described. It consists of 12 independent units for testing specimens having a 4-in. reduced section. Gii a 0.505 -in. diameter specimen, loads from 80 to $90,000 \mathrm{lb}$./in. ${ }^{2}$ can be conveniently applied. The temperature is controlled within $\pm 5^{\circ} \mathrm{F}$ up to $1,200^{\circ} \mathrm{F}$, and the extensometer readings have a probable error of less than 0.00004 in. The extension is measured between the shoulders of the specimen, so that a correction is required, but the accuracy of the corrected extension averages within $1 \frac{1}{2}$ percent.

Time-extension data were obtained with specimens of severely coldworked nickel-copper alloy. The stress range investigated covered the full range of the apparatus, while the temperatures used varied from $700^{\circ}$ to $1,225^{\circ} \mathrm{F}$. In general, one specimen was tested at a single temperature and a series of different stresses.

The results show that a nearly constant creep rate, characteristic of a stress-temperature combination, was attained after a period of adjustment. The use of a single specimen for a series of stresses allowed more rapid determination of this characteristic rate than a single load test. With a single specimen, therefore, a series of characteristic creep rates could be determined, for different applied stresses. One series of tests, made under a single load at a series of different temperatures, resulted in little or no period of adjustment, yet these rates were consistent with those determined from the constant-temperature tests. The results as a whole indicate that there was only one characteristic rate for each stress-temperature combination irrespective of the previous stresses or temperatures.

Diagrams are given showing the relationship between the variables stress, temperature, and creep rate. No mathematical function could be found to describe the creep test data.

Daniel H. Gagon, formerly of this Division, assisted with the construction of the furnaces and with the measurement of extension during tests.

\section{REFERENCES}

[1] W. A. Tucker and S. E. Sinclair, Creep and structural stability of nickel-chromium-iron alloys at $1,600^{\circ} \mathrm{F}, \mathrm{BS} \mathrm{J}$. Research 10, 851 (1933) RP572.

[2] F. H. Norton, Pyrometry in connection with creep tests. Symposium on Temperature: Its Measurement and Control in Science and Industry, p. 963 (Reinhold Publishing Co., New York, N. Y., 1939).

[3] A. E. White and C. L. Clark, Creep characteristics of metals at elevated temperatures, Trans. Am. Soc. Steel Treating 21, 1 (1933).

[4] J. J. Kanter and E. A. Sticha, Creep rates from tests of short duration, Trans. Am. Soc. Metals 28, 257 (1940).

[5] A. Eichinger, Mathematical treatment of creep curves, Arch. Eisenhüttenw. 13, 397 (1940).

WASHington, January 8, 1942. 